\title{
Decomposing the Impact of Alternative Technology Sets on Future Carbon Emissions Growth ${ }^{1}$
}

\author{
Karen Fisher-Vanden ${ }^{2}$ \\ Pennsylvania State University \\ Kathryn Schu \\ Pennsylvania State University \\ lan Sue Wing \\ Boston University \\ Katherine Calvin \\ PNNL/JGCRI
}

June 27, 2011

\footnotetext{
${ }^{1}$ This work was supported by the US Environmental Protection Agency, Office of Air and Radiation, Office of Atmospheric Programs, Climate Change Division. We thank participants of the Asian Modeling Exercise for valuable comments on a previous draft.

${ }^{2}$ Corresponding author: Department of Agricultural Economics and Rural Sociology, Pennsylvania State University, 112E Armsby Building, University Park, PA 16802; phone: 814-867-2752; fax: 814-865-3746.
} 


\title{
Decomposing the Impact of Alternative Technology Sets on Future Carbon Emissions Growth
}

\begin{abstract}
What are the drivers of future global carbon dioxide $\left(\mathrm{CO}_{2}\right)$ emissions growth and how would the availability of key energy supply technologies change their relative importance? In this paper, we apply a novel index number decomposition technique to the results of a multi-region, multisector computable general equilibrium model to quantify the influence of five factors on the growth of future carbon emissions: (1) growth in global economic activity; (2) shifts in the regional composition of gross world product; (3) shifts in the sectoral composition of regions' GDP; (4) changes in sectors' energy-output ratios; and (5) changes in the $\mathrm{CO}_{2}$ intensity of energy sources. We elucidate how the relative importance of these factors changes in response to the imposition of a global carbon tax and alternative assumptions about the future availability of key energy supply technologies. Rising global economic activity and shifts in regional composition put upward pressure on emissions while changes in energy and emission intensity and the sectoral output mix have attenuating effects. A global emission tax that increases over time slows economic expansion and shifts the fuel mix, with the most pronounced impacts on China, India, and Russia. Limited availability of carbon capture and storage, nuclear, and hydroelectric generation all lead to upward shifts in the long-run marginal abatement cost curve, causing some countries to choose to pay the tax rather than abate.
\end{abstract}

JEL Classification: D58, Q4, Q54, O1,

Keywords: Asia, energy use, carbon emissions, global climate change, computable general equilibrium, technological change. 


\section{Introduction}

What are the drivers of future global carbon dioxide $(\mathrm{CO} 2)$ emissions growth and how would the availability of key energy supply technologies change their relative importance? In this paper, we apply a novel index number decomposition technique to the results of a multiregion, multi-sector computable general equilibrium model to quantify the influence of five factors on the growth of future carbon emissions: (1) growth in global economic activity; (2) shifts in the regional composition of gross world product; (3) shifts in the sectoral composition of regions' GDP; (4) changes in sectors' energy-output ratios; and (5) changes in the $\mathrm{CO} 2$ intensity of energy sources. We elucidate how the relative importance of these factors changes in response to the imposition of a global carbon tax and alternative assumptions about the future availability of key energy supply technologies.

Copeland and Taylor (1994) is one of the first studies to decompose the scale, technique, and composition effects on environmental quality resulting from trade liberalization in a static two-country general equilibrium model. The authors point out that trade liberalization can affect environmental quality in three ways. First, income gains from trade could lead to greater demand for environmental quality and thus the adoption of cleaner technologies (technique effect). Second, greater trade openness should lead to higher economic activity which, all else equal, should lead to higher levels of pollution (scale effect). Lastly, trade openness could lead to shifts in the composition of output within a country in reaction to international competition and changes in income levels. Similar to Copeland and Taylor (1994), we are interested in decomposing the factors driving the change in emissions due to the implementation of a carbon tax under alternative technology scenarios. 
Imposing a carbon tax on an economy affects emissions in a number of ways. First, it will spur the adoption of less carbon-intensive technologies in production. This can affect carbon emissions by lowering the amount of energy used in production (INTENSITY) and/or shifting to less carbon-intensive forms of energy (MIX). Second, imposing a carbon tax will increase the unit cost of fossil fuel-based energy. This will increase the price of carbon-intensive goods, leading to a substitution away from these goods which will shift the sectoral composition of the economy toward less carbon-intensive industries (SECTORAL). Higher prices will also lead to fewer goods sold which will lower economic activity (ACTIVITY). Lastly, higher prices as a result of the carbon tax will change a country's trade competitiveness, leading to a shift in production to countries less burdened by the tax (REGIONAL). Decomposing the relative importance of these factors in explaining the change in carbon emissions is important for identifying the channels by which policies affect emissions. This insight can shed light on the key model assumptions and functional relationships that are driving the results. Comparing these decompositions results under alternative technologies set assumptions provides a type of sensitivity analysis—e.g., how do different assumptions regarding the availability of technologies influence the channels by which emissions are determined?

We compare a reference scenario and four alternative technology scenarios: (a) a "no policy" reference scenario (Scenario 1a) that assumes the unrestricted use of nuclear and hydroelectric generation; (b) the Scenario $2 \mathrm{~b}$ carbon tax case that assumes the unrestricted use of nuclear, hydroelectric generation, and carbon capture and storage (CCS); (c) the Scenario $2 b$ carbon tax case that assumes the unrestricted use of nuclear and hydro, but restricts the use of CCS; (d) the Scenario 2b carbon tax case that assumes the unrestricted use of CCS and hydro, but includes restrictions on the capacity of nuclear power; and (e) the Scenario $2 \mathrm{~b}$ carbon tax 
case that assumes the unrestricted use of nuclear and CCS, but includes restrictions on the growth of hydro.

With restrictions on the use of CCS, we would expect the marginal abatement cost curve (MAC) to rise, leading to less abatement, higher emissions, and thus higher carbon tax revenue. To avoid distortions, we recycle the revenue lump-sum to household income. Higher nondistortionary taxes are expected to create an additional burden on the economy, leading to lower economic activity. Since CCS provides a carbon-free source of energy, we expect higher energy intensity when CCS is available. Restrictions on the use of CCS will likely force the economy to reduce the energy intensity of the economy. CCS is heavily used with IGCC which is coalbased. Therefore, restrictions on the use of CCS will likely shift the energy mix away from coal and toward less carbon-intensive forms of energy. However, CCS implies a carbon-free use of coal which should lead to a lower carbon-intensity of energy ratio than when CCS is restricted.

Restricting the use of nuclear and hydroelectricity — two forms of "clean" energy—will also increase the MAC. We would therefore expect the results to be similar to the restricted CCS case in terms of the mix of energy. The availability of CCS means that more coal can be consumed carbon-free and therefore restricting CCS implies a higher carbon-to-energy ratio. When we restrict nuclear and hydroelectric generation, we expect the mix to shift in the same direction, since cleaner forms of energy are not as available.

The paper is organized as follows. Section 2 provides a brief description of the model which is further elaborated in Appendix A. Section 3 presents the simulation results including a description of the decomposition technique applied in our analysis. Lastly, Section 4 offers concluding remarks. 


\section{An Economic-Energy Model-Phoenix}

This work utilizes a newly-developed multi-regional, multi-sectoral computable general equilibrium (CGE) model, Phoenix, developed though a research collaboration between Boston University, the Pennsylvania State University, and Pacific Northwest National Laboratory/University of Maryland's Joint Global Change Research Institute.

In the Phoenix model, the world is divided into twenty-four regions, each with twenty-six industrial sectors and two representative agents, allowing us to measure the relative importance of shifts in the contribution of regional output and sectoral output within a region to future carbon emissions growth. The regional identities include both individual countries (e.g., USA, Brazil, Canada) and aggregates of countries within a particular geographic region (e.g., Middle East, and North Africa). Each industrial sector produces a single output that is consumed by the representative consumer and the government and used by the production sectors as intermediate inputs. The Global Trade Analysis Project (GTAP) version 7 database (Badri and Walmsley, 2008) is used to generate the social accounting matrices for each of the 24 regions.

Producer and consumer behavior is modeled using nested constant elasticity of substitution (CES) production and consumption functions. There are four factors of production (land, natural resources, labor, and capital) that are owned by the representative regional household and are rented out to the respective production sectors. With a given technology, the industrial sectors combine the primary factors of production with material and energy inputs to produce final consumption goods. The model is solved when the general equilibrium conditions of market clearance, income balance, and zero profits are satisfied.

Particular attention is paid to energy production. In addition to electricity generation, there are four intermediate energy commodities: crude oil, refined oil products, coal, and natural 
gas. Coal gasification and liquid biomass are introduced as backstop technologies for the gas and refined oil commodities, respectively. Electricity generation is decomposed into production by coal, gas, oil, biomass, nuclear, wind, solar, and hydro, using the calibration procedure described in Sue Wing (2006a, 2006b). Carbon capture and sequestration technology is available for a portion of the electricity generated by coal and gas.

International trade is modeled using Armington and Heckscher-Ohlin (HO) trade functions. We assume $\mathrm{HO}$ trade for crude oil and gas. As a result, all countries experience the same import price for these goods. The remaining 24 goods are traded using an Armington model, allowing the import price to vary by region. In each sector there is a tradeoff between the domestically produced and imported goods that is defined by the elasticity of substitution between imported and domestic commodities.

Further details on the model can be found in Appendix A.

\section{Simulation Results}

We are interested in decomposing the factors driving differences in emissions between five scenarios: (1) Scenario 1 or "reference;" (2) Scenario 2b; (3) Scenario 2b without a carbon capture and storage (CCS) option; (4) Scenario 2b with no new nuclear power capacity added after 2005 and existing capacity phased out completely by 2050; (5) Scenario 2b with no new hydroelectric capacity added after 2005 and existing capacity phased out over 100 years.

To understand the factors driving differences in emissions across these five scenarios, we decompose the effects of factor substitution and output substitution on the change in carbon emissions between the years 2005 and 2075. We employ a decomposition method based on the Kaya identity (Kaya and Yokobori, 1997) as described below. The Kaya identity is: 


$$
\begin{aligned}
\mathcal{C} & =\sum_{j} \sum_{r} \mathcal{Q} \times \frac{Q_{r}}{\mathcal{Q}} \times \frac{q_{j, r}}{Q_{r}} \times \frac{e_{j, r}}{q_{j, r}} \times \frac{c_{j, r}}{e_{j, r}} \\
& =\mathcal{Q} \times \sum_{r}\left[\frac{Q_{r}}{\mathcal{Q}} \times \sum_{j}\left(\frac{q_{j, r}}{Q_{r}} \times \frac{e_{j, r}}{q_{j, r}} \times \frac{c_{j, r}}{e_{j, r}}\right)\right]
\end{aligned}
$$

where $c_{j, r}=$ emissions in industry $j$ and region $r$ and $\mathcal{C}=\sum_{j} \sum_{r} c_{j, r}=$ global emissions (in million tons $\mathrm{CO}_{2}$ ); $\mathcal{Q}=$ gross world product, $Q_{r}=\mathrm{GDP}$ in region $r$, and $q_{r, j}=$ gross output of industry $j$ in region $r$ (all in billion 2004 US \$); and $e_{r, j}=$ final energy use in industry $j$ and region $r$ (in EJ). Taking log differentials, we obtain the Divisia index number decomposition

$$
\begin{aligned}
d \log \mathcal{C} & =d \log \mathcal{Q}+d \log \sum_{r}\left[\frac{Q_{r}}{\mathcal{Q}} \times \sum_{j}\left(\frac{q_{j, r}}{Q_{r}} \times \frac{e_{j, r}}{q_{j, r}} \times \frac{c_{j, r}}{e_{j, r}}\right)\right] \\
& =d \log \mathcal{Q}+\sum_{r} S_{r}\left[d \log \frac{Q_{r}}{\mathcal{Q}}+d \log \sum_{j}\left(\frac{q_{j, r}}{Q_{r}} \times \frac{e_{j, r}}{q_{j, r}} \times \frac{c_{j, r}}{e_{j, r}}\right)\right] \\
& =d \log \mathcal{Q}+\sum_{r} S_{r}\left[d \log \frac{Q_{r}}{\mathcal{Q}}+\sum_{j} s_{j, r}\left(d \log \frac{q_{j, r}}{Q_{r}}+d \log \frac{e_{j, r}}{q_{j, r}}+d \log \frac{c_{j, r}}{e_{j, r}}\right)\right] \\
= & d \log \mathcal{Q}+\sum_{r} S_{r} d \log \frac{Q_{r}}{\mathcal{Q}}+\sum_{r} S_{r}\left(\sum_{j} s_{j, r} d \log \frac{q_{j, r}}{Q_{r}}\right) \\
& +\sum_{r} S_{r}\left(\sum_{j} s_{j, r} d \log \frac{e_{j, r}}{q_{j, r}}\right)+\sum_{r} S_{r}\left(\sum_{j} s_{j, r} d \log \frac{c_{j, r}}{e_{j, r}}\right)
\end{aligned}
$$

where the weights $S_{r}=C_{r} / \mathcal{C}$ and $s_{j, r}=c_{j, r} / C_{r}$ respectively denote region $r$ 's share of global emissions and sector $j$ 's share of the $\mathrm{CO}_{2}$ emitted by the region in which it resides.

If we are interested in decomposing the growth in emissions between two time periods, $t$ $=0$ and $t=T$, we can implement eq. (3) empirically as follows: 


$$
\begin{aligned}
& \underbrace{\log \left(\frac{\mathcal{C}_{T}}{\mathcal{C}_{0}}\right)}_{G_{\mathrm{CO}_{2}}}=\underbrace{\log \left(\frac{\mathcal{Q}_{T}}{\mathcal{Q}_{0}}\right)}_{G_{\text {Activity }}}+\underbrace{\sum_{r} \hat{S}_{r} \log \left(\frac{Q_{r, T}}{\mathcal{Q}_{T}} / \frac{Q_{r, 0}}{\mathcal{Q}_{0}}\right)}_{G_{\text {Regional }}}+\underbrace{\sum_{r} \hat{S}_{r}\left[\sum_{j} \hat{S}_{j, r} \log \left(\frac{q_{j, r, T}}{Q_{r, \mathrm{~T}}} / \frac{q_{j, r, 0}}{Q_{r, 0}}\right)\right]}_{G_{\text {Sectoral }}} \\
& +\underbrace{\sum_{r} \hat{S}_{r}\left[\sum_{j} \hat{S}_{j, r} \log \left(\frac{e_{j, r, \mathrm{~T}}}{q_{j, r, \mathrm{~T}}} / \frac{e_{j, r, 0}}{q_{j, r, 0}}\right)\right]}_{G_{\text {Intensity }}}+\underbrace{}_{G_{\text {Mix }} \sum_{r} \hat{S}_{r}\left[\sum_{j} \hat{s}_{j, r} \log \left(\frac{c_{j, r, \mathrm{~T}}}{e_{j, r, \mathrm{~T}}} / \frac{c_{j, r, 0}}{e_{j, r, 0}}\right)\right]}
\end{aligned}
$$

where the weights are approximated by the Tornqvist formula, $\hat{S}_{r}=0.5\left(C_{r, T} / \mathcal{C}_{T}+C_{r, 0} / \mathcal{C}_{0}\right)$ and $\hat{s}_{j, r}=0.5\left(c_{j, r, T} / C_{r, T}+c_{j, r, 0} / C_{r, 0}\right)$. The resulting sums of log differentials may therefore be interpreted as the inter-period rates of change, which allows the right-hand side of eq. (3) to intuitively partition the growth of $\mathrm{CO}_{2}$ emissions into the contributions of five driving forces: the scale effect of growth in global economic activity $\left(G_{\text {Activity }}\right)$; two output composition effects, one regional $\left(G_{\text {Regional }}\right)$ and the other sectoral $\left(G_{\text {Sectoral }}\right)$; and two technique effects: changes in sectors' energy-output ratios $\left(G_{\text {Intensity }}\right)$ and in the $\mathrm{CO}_{2}$ intensity of their energy sources $\left(G_{\text {Mix }}\right)$. Finally, we stress that since the decomposition method is a numerical approximation in which the weights given above are estimates, a residual term also exists.

While the customary approach when taking eq. (3) to the data is to utilize the information available at the end-points of the horizon $[0, T]$, we sought to make use of the entire trajectory of simulated emissions, energy use, and output, which is provided by our CGE model on a five-year time step. In particular, experiments with different empirical formulations of (3) indicated that the large increases in these series over our long simulation horizon (2005-2075) led the Tornqvist approximation to generate an unacceptable residual when applied to just the end-point values. To address this problem, we employed the trick of computing sequences of five-year rates of change $\left(G_{\ell, t}\right.$ for factor $\ell$ in adjacent periods $t$ and $\left.t-1\right)$, which were then chained together starting from unity in the initial period: 


$$
D_{\ell}=\prod_{t=1}^{T} \exp \left(G_{\ell, t}\right)
$$

The resulting period- $T$ index numbers indicate the cumulative impact of each factor relative to the initial point, comparable to growth factors generated by other decomposition techniques.

Eq. (4)'s key advantage is that it yields an approximate decomposition of the inter-period changes in global and regional emissions into quantities of $\mathrm{CO}_{2}$ that are attributable to the five factors above. Our decomposition is based on the fact that over a sufficiently short time scale, the rate of growth of total emissions can be approximated using the centered difference formula $G_{\mathrm{CO}_{2}, t}=\sum_{\ell} G_{\ell, t}=\log \left(\mathcal{C}_{t} / \mathcal{C}_{t-1}\right) \approx 2\left(\mathcal{C}_{t}-\mathcal{C}_{t-1}\right) /\left(\mathcal{C}_{t}+\mathcal{C}_{t-1}\right)$, which implies that the interperiod change in emissions is approximately:

$$
\Delta \mathcal{C}_{t}=\mathcal{C}_{t}-\mathcal{C}_{t-1} \approx \sum_{\ell} \delta_{\ell, t}=\sum_{\ell} G_{\ell, t} \cdot 0.5\left(\mathcal{C}_{t}+\mathcal{C}_{t-1}\right)
$$

where the individual components of emissions corresponding to the various factors, $\delta_{\ell, t}$, may take on positive or negative values. Similar to eq. (4), we track the cumulative increase or decline in emissions in response to a given factor by summing the inter-period components over the simulation horizon:

$$
\Delta_{\ell}=\sum_{t=1}^{T} \delta_{\ell, t}
$$

\subsection{Scenario 1a ("Reference")}

Results from our decomposition analysis of Scenario 1a are shown in Table 1. The first panel shows the values of $D_{\text {Activity }}, D_{\text {Regional }}, D_{\text {Sectoral }}, D_{\text {Intensity }}$, and $D_{\text {Mix }}$, expressed as percentage changes from 2005, to explain the change in emissions between 2005 and 2075. The results imply that world carbon dioxide emissions would be 546\% higher in 2075 than in 2005, all else 
equal, due to changes in world economic activity. This is dampened by reductions in energy intensity — carbon dioxide emissions decline by 57\%, all else equal, due to reductions in energy intensity.

The second panel of Table 1 provides these results in terms of million metric tons of carbon dioxide. Figure 1 shows these results for the world. The results imply that economic activity would lead to an increase in world emissions of 89,097 million metric tons of $\mathrm{CO}_{2}$ by 2075, all else equal. This is dampened by a reduction in world $\mathrm{CO}_{2}$ emissions of 40,365 MT due to reductions in energy intensity, all else equal. Total $\mathrm{CO}_{2}$ emissions grow by 45,539 MT between the years 2005 and 2075 in the reference case.

These results show that future global carbon emission growth in the Reference case is driven primarily by overall economic growth (ACTIVITY) and shifts in the regional composition of output (REGIONAL). Changes in the energy mix (MIX), sectoral change (SECTORAL), and energy intensity (INTENSITY) apply downward pressure on emissions over time, dampening the effects of higher economic growth and changes in the regional composition of output which put upward pressure on emissions. The greatest downward pressure on emissions comes from changes in energy intensity. Changes in the mix of energy is not a large contributor to lowering the growth of emissions.

There are also significant differences across countries. In Japan, Korea, Brazil, the U.S., and the EU, changes in energy intensity have a smaller effect on lowering the future growth of emissions than other countries. This effect is most prominent in countries such as China, India, Indonesia, and Russia where a large potential for energy efficiency improvements exists. We also see that sectoral change has a much larger impact on lowering carbon emissions in countries 
like China where large structural changes are occurring. Across these nine countries, however, we see a much smaller effect from shifts in the energy mix.

Significant improvements in energy efficiency and sectoral change in China and India, in particular, play an important role in dampening growth in $\mathrm{CO}_{2}$ emissions resulting from rapid economic growth. As shown in the table, China's and India's emissions would be $2078 \%$ and 3064\% higher, respectively, in 2075 than in 2005 as a result of economic growth. However, sectoral change and declines in energy intensity dampen this effect, resulting in $\mathrm{CO}_{2}$ emissions $359 \%$ and $430 \%$ times higher in China and India, respectively, in 2075. In Japan, on the other hand, economic growth is small over time, causing the dampening effects on emissions from sectoral change, improvements in energy intensity, and shifts in the energy mix to more than offset the increase in emissions from economic growth. As a result, emissions in Japan are $17 \%$ higher in 2075 than in 2005.

\subsection{Scenario $2 c$}

Imposing a global carbon tax trajectory as in Scenario 2c lowers the upward pressure on emissions caused by higher economic growth and changes in the regional composition of output, but these factors still cause emissions to rise over time, as shown in Table 2. The dampening effect on the growth of $\mathrm{CO}_{2}$ emissions from changes in the sectoral composition of output, the mix of energy, and energy intensity increases as a result of the carbon tax. In absolute terms, the carbon tax has the largest effect on world emissions from economic growth. As shown in the last panel of Table 2, growth in emissions from economic activity falls by $43 \%$ due to the tax. The tax also has a large effect on the contribution of changes in the energy mix — as a result of the 
carbon tax, changes in the energy mix lowers emissions by 53\% in 2075 (all else equal) whereas without the carbon tax, this effect lowers emissions by only $11 \%$ in 2075 .

The effects of the carbon tax are not uniform across countries. Except for Brazil and India, $\mathrm{CO}_{2}$ emissions in each country are lower in 2075 than in 2005. However, in Brazil and India, emissions are still higher in 2075 than in 2005, although emissions are significantly less than in the reference case. In fact, as shown in the last panel of Table 2, the decrease in emissions due to the carbon tax is largest in Brazil, China, India, and Russia. This implies that these countries are choosing to abate rather than pay the tax - thus, the marginal abatement cost curve must be lower in these countries.

The carbon tax has a large impact on lowering the effect of economic growth on carbon emissions in countries like Russia, China, and India, whereas this impact is small in countries like Japan, EU, the US, and Korea. Except for the EU, US, Korea, and Japan, the carbon tax has the largest effect on the contribution of economic activity on emissions. The carbon tax's effect on energy intensity is largest in countries like the US, Japan, the EU, and Korea whereas the tax's effect on the contribution of changes in the energy mix is largest in Russia, China, and India. In these countries, the model assumes large improvements in autonomous energy efficiency in the Reference case. Imposing a tax implies there is little room for energy efficiency improvements in reaction to the tax. Therefore, reductions must be achieved through declines in economic growth and shifts in the energy mix.

These results highlight the different growth patterns across countries and differences in the relative importance of the five key drivers affecting carbon emissions growth. These results also emphasize the differences in strategies that countries will take in response to a global carbon tax. Lastly, these results point out that not only will higher economic growth lead to higher 
future carbon emissions, but shifts in the regional composition of output will also be a key contributor to higher future carbon emissions growth.

\subsection{Scenario $2 \mathrm{c}$ without $\mathrm{CCS}$}

The above results assume the unrestricted availability of carbon capture and storage (CCS), hydroelectric, and nuclear power generation. How do these decomposition results change if we restrict the availability of these technologies? As shown in the bottom panel of Table 3, when we restrict the availability of CCS, we find that emissions are higher or unchanged in every country than when CCS is unrestricted. This reflects the higher marginal abatement cost in the restricted CCS case, causing countries to choose to pay the tax rather than abate. This is especially the case in countries such as China and India which are intensive users of coal. In the case of Russia, we see a large drop in economic growth when CCS is restricted since Russia is a large user of NGCC with CCS when the tax is imposed without technology restrictions. Eliminating the use of CCS forces Russia to lower economic activity to reduce emissions.

When CCS is restricted, we also see in certain countries the relative contribution shift from energy mix to energy intensity; that is, a tax on emissions leads to higher energy efficiency improvements in the restricted CCS case and less of a shift to other forms of energy. When CCS is available, more carbon-free energy can be consumed which leads to a lower carbon to energy $(\mathrm{C} / \mathrm{E})$ ratio and a higher energy intensity $(\mathrm{E} / \mathrm{Q})$ ratio. Thus, restricting CCS means that the economy will need to rely more on energy intensity improvements to reduce emissions. This emphasis on intensity rather than mix when CCS is restricted is most prominent in China and India where coal is dominant. The availability of CCS means that these countries can continue to burn coal without the emissions from coal. Therefore, the contribution of energy mix when 
CCS is available is larger in these countries. These results provide a type of sensitivity analysis to assumptions made regarding the set of available technologies and the value of these technologies.

\subsection{Scenario $2 \mathrm{c}$ with restrictions on nuclear}

Table 4 shows results from Scenario $2 \mathrm{c}$ where we assume no new growth in nuclear capacity and a complete phase out of existing nuclear capacity by 2050 . For most countries, emissions change very little from the Scenario $2 c$ case without restrictions on nuclear. Emissions in Korea, however, are 10\% higher due to Korea's large installed nuclear capacity; thus, when nuclear is restricted, Korea is forced to pay the tax rather than abate emissions. Except for Russia, the contribution of economic activity to emissions is slightly lower when nuclear is restricted. Eliminated a carbon-free source of energy will increase the marginal abatement cost curve, causing a slight drop in economic growth. In countries with larger shares of nuclear in primary energy (e.g., EU, Japan, US), restricting nuclear in the carbon tax case leads to a shift in the mix of energy toward less carbon-intensive forms of energy.

\subsection{Scenario $2 \mathrm{c}$ with restrictions on hydropower}

Table 5 shows the results from restricting the growth in hydroelectric generating capacity. In this case, we assume a slower growth in new hydro capacity than in the Scenario $2 \mathrm{c}$ case without restrictions. We find the differences from the unrestricted case to be small since by 2075 there still will be little difference in the installed capacity of hydroelectricity, given its long lifetime. Only China and India experience an increase in 2075 emissions. This is due to the fact that when hydro is restricted, countries like China and India, which have larger shares of 
hydroelectric generation, are unable to achieve the level of reductions that is possible when hydroelectric generation is unrestricted and are therefore forced to emit more and pay the tax. Brazil, a large hydroelectric producer, experiences a slight decline in 2075 emissions with the tax when hydro is restricted; however, Brazil takes a hit to economic activity since Brazil's only option to reduce emissions if hydro is restricted is to reduce economic activity.

\section{Conclusions}

This paper not only identifies the key drivers to changes in emissions over time, but also provides a type of sensitivity analysis to the importance of technology assumptions in a multiregion multi-sector model like Phoenix. A few key points emerge from our analysis. First, economic growth and shifts in the regional composition of output are the largest contributors to increases in emissions over time although decreases in energy intensity and shifts in the sectoral composition of output dampen the growth in emissions.

Second, imposing a tax on emissions has the largest impact on lowering the upward pressure on emissions from economic activity and lowering the carbon intensity of energy, although this is most prominent in countries like China, India, and Russia. Third, if we restrict the use of CCS in this tax case, the marginal abatement cost curve shifts up, causing some countries to choose to pay the tax rather than abate and increasing the carbon intensity of energy. Fourth, if we eliminate new nuclear capacity and phase out nuclear by 2050, we get a similar result-some countries will choose to pay the tax rather than abate due to the increase in the MAC. Lastly, lowering the growth of new hydropower capacity does little to change the tax case results due to the long lifetime of hydropower facilities. 


\section{Table 1}

\begin{tabular}{|c|c|c|c|c|c|c|c|c|c|c|}
\hline & \multicolumn{10}{|c|}{ Reference case } \\
\hline & World & Brazil & China & EU15 & Indonesia & India & Japan & Korea & Russia & USA \\
\hline \multicolumn{11}{|c|}{ Cumulative change in factors influencing the growth of $\mathrm{CO}_{2}$ emissions $(D), 2005-2075$} \\
\hline \multirow{5}{*}{$\begin{array}{l}\text { Activity } \\
\text { Regional } \\
\text { Sectoral } \\
\text { Intensity } \\
\text { Mix }\end{array}$} & $546 \%$ & $1274 \%$ & $2078 \%$ & $231 \%$ & $1205 \%$ & $3064 \%$ & $107 \%$ & $334 \%$ & $1206 \%$ & $325 \%$ \\
\hline & $59 \%$ & $\mathrm{n} / \mathrm{a}$ & $\mathrm{n} / \mathrm{a}$ & $\mathrm{n} / \mathrm{a}$ & $n / a$ & $\mathrm{n} / \mathrm{a}$ & $\mathrm{n} / \mathrm{a}$ & $\mathrm{n} / \mathrm{a}$ & $\mathrm{n} / \mathrm{a}$ & $\mathrm{n} / \mathrm{a}$ \\
\hline & $-31 \%$ & $-36 \%$ & $-47 \%$ & $-29 \%$ & $-19 \%$ & $-26 \%$ & $-26 \%$ & $-24 \%$ & $-27 \%$ & $-32 \%$ \\
\hline & $-57 \%$ & $-48 \%$ & $-59 \%$ & $-42 \%$ & $-68 \%$ & $-73 \%$ & $-30 \%$ & $-27 \%$ & $-62 \%$ & $-49 \%$ \\
\hline & $-11 \%$ & $-17 \%$ & $-2 \%$ & $-20 \%$ & $-18 \%$ & $-15 \%$ & $-23 \%$ & $-11 \%$ & $-8 \%$ & $-11 \%$ \\
\hline Total & $168 \%$ & $276 \%$ & $359 \%$ & $8 \%$ & $175 \%$ & $430 \%$ & $-17 \%$ & $113 \%$ & $229 \%$ & $31 \%$ \\
\hline \multicolumn{11}{|c|}{ Cumulative components of change in emissions $(\Delta), 2005-2075$, million metric tons of $\mathrm{CO}_{2}$} \\
\hline \multirow{5}{*}{\begin{tabular}{|l} 
Activity \\
Regional \\
Sectoral \\
Intensity \\
Mix \\
\end{tabular}} & 89097 & 1741 & 39691 & 4314 & 1833 & 10029 & 716 & 956 & 7772 & 10175 \\
\hline & 19965 & 0 & 0 & 0 & 0 & 0 & 0 & 0 & 0 & 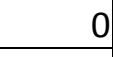 \\
\hline & -17764 & -323 & -8643 & -1248 & -177 & -690 & -292 & -194 & -1091 & -2748 \\
\hline & -40365 & -462 & -12197 & -2018 & -852 & -4106 & -343 & -216 & -2696 & -4658 \\
\hline & -5395 & -129 & -403 & -785 & -154 & -482 & -263 & -76 & -255 & -865 \\
\hline Total & 45539 & 828 & 18447 & 262 & 651 & 4751 & -183 & 469 & 3730 & 1905 \\
\hline
\end{tabular}

Figure 1

Reference case, World, 2075

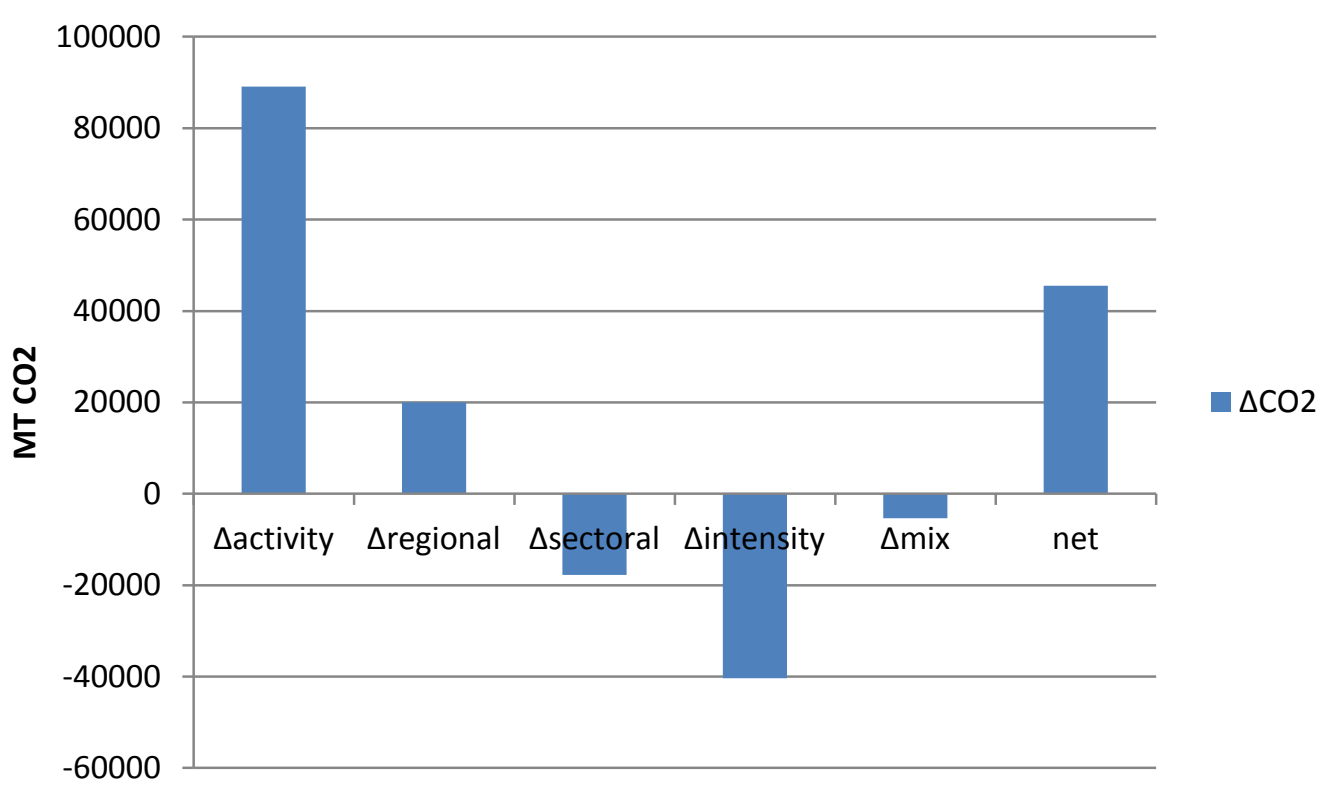




\section{Table 2}

\begin{tabular}{|c|c|c|c|c|c|c|c|c|c|c|}
\hline & \multicolumn{10}{|c|}{ Scenario 2c, All Energy Supply Technologies } \\
\hline & World & Brazil & China & EU15 & Indonesia & India & Japan & Korea & Russia & USA \\
\hline \multicolumn{11}{|c|}{ Cumulative $\%$ change in factors influencing the growth of $\mathrm{CO}_{2}$ emissions $(D), 2005-2075$} \\
\hline \multirow{5}{*}{$\begin{array}{l}\text { Activity } \\
\text { Regional } \\
\text { Sectoral } \\
\text { Intensity } \\
\text { Mix } \\
\end{array}$} & $503 \%$ & $1227 \%$ & $1850 \%$ & $222 \%$ & $1124 \%$ & $2824 \%$ & $103 \%$ & $325 \%$ & $939 \%$ & $313 \%$ \\
\hline & $43 \%$ & & & & & & & & & \\
\hline & $-46 \%$ & $-48 \%$ & $-64 \%$ & $-34 \%$ & $-34 \%$ & $-42 \%$ & $-34 \%$ & $-38 \%$ & $-42 \%$ & $-43 \%$ \\
\hline & $-77 \%$ & $-73 \%$ & $-80 \%$ & $-67 \%$ & $-84 \%$ & $-84 \%$ & $-58 \%$ & $-61 \%$ & $-83 \%$ & $-75 \%$ \\
\hline & $-53 \%$ & $-28 \%$ & $-52 \%$ & $-55 \%$ & $-42 \%$ & $-59 \%$ & $-53 \%$ & $-37 \%$ & $-63 \%$ & $-52 \%$ \\
\hline Total & $-50 \%$ & $35 \%$ & $-31 \%$ & $-69 \%$ & $-24 \%$ & $7 \%$ & $-74 \%$ & $-36 \%$ & $-62 \%$ & $-71 \%$ \\
\hline \multicolumn{11}{|c|}{ Cumulative components of change in emissions $(\Delta), 2005-2075$, million metric tons of $\mathrm{CO}_{2}$} \\
\hline \multirow{5}{*}{$\begin{array}{l}\text { Activity } \\
\text { Regional } \\
\text { Sectoral } \\
\text { Intensity } \\
\text { Mix }\end{array}$} & 34167 & 960 & 13748 & 2325 & 871 & 3379 & 375 & 552 & 2197 & 5244 \\
\hline & 7482 & & & & & & & & & \\
\hline & -12457 & -248 & -4878 & -879 & -143 & -559 & -259 & -173 & -574 & -2126 \\
\hline & -29032 & -482 & -7534 & -2097 & -634 & -1886 & -443 & -357 & -1828 & -5092 \\
\hline & -13997 & -126 & -3088 & -1658 & -181 & -894 & -489 & -173 & -853 & -2482 \\
\hline Total & -13836 & 104 & -1751 & -2309 & -87 & 40 & -816 & -151 & -1059 & -4456 \\
\hline \multicolumn{11}{|c|}{ Cumulative components of change in emissions $(\Delta), \%$ difference from Reference Case } \\
\hline \multirow{5}{*}{\begin{tabular}{|l} 
Activity \\
Regional \\
Sectoral \\
Intensity \\
Mix \\
\end{tabular}} & $-43 \%$ & $-47 \%$ & $-228 \%$ & $-9 \%$ & $-81 \%$ & $-240 \%$ & $-4 \%$ & $-9 \%$ & $-267 \%$ & $-11 \%$ \\
\hline & $-16 \%$ & & & & & & & & & \\
\hline & $-15 \%$ & $-12 \%$ & $-17 \%$ & $-5 \%$ & $-15 \%$ & $-16 \%$ & $-9 \%$ & $-14 \%$ & $-15 \%$ & $-11 \%$ \\
\hline & $-20 \%$ & $-24 \%$ & $-21 \%$ & $-25 \%$ & $-16 \%$ & $-11 \%$ & $-28 \%$ & $-34 \%$ & $-21 \%$ & $-26 \%$ \\
\hline & $-42 \%$ & $-12 \%$ & $-49 \%$ & $-35 \%$ & $-24 \%$ & $-44 \%$ & $-30 \%$ & $-26 \%$ & $-54 \%$ & $-40 \%$ \\
\hline Total & $-218 \%$ & $-241 \%$ & $-390 \%$ & $-77 \%$ & $-199 \%$ & $-423 \%$ & $-57 \%$ & $-150 \%$ & $-292 \%$ & $-102 \%$ \\
\hline
\end{tabular}




\section{Table 3}

\begin{tabular}{|c|c|c|c|c|c|c|c|c|c|c|}
\hline & \multicolumn{10}{|c|}{ Scenario $2 \mathrm{c}$ without CCS } \\
\hline & World & Brazil & China & EU15 & Indonesia & India & Japan & Korea & Russia & USA \\
\hline \multicolumn{11}{|c|}{ Cumulative \% change in factors influencing the growth of $\mathrm{CO}_{2}$ emissions $(D), 2005-2075$} \\
\hline \multirow{5}{*}{$\begin{array}{l}\text { Activity } \\
\text { Regional } \\
\text { Sectoral } \\
\text { Intensity } \\
\text { Mix } \\
\end{array}$} & $502 \%$ & $1226 \%$ & $1851 \%$ & $222 \%$ & $1122 \%$ & $2825 \%$ & $103 \%$ & $326 \%$ & $908 \%$ & $313 \%$ \\
\hline & $44 \%$ & $0 \%$ & $0 \%$ & $0 \%$ & $0 \%$ & $0 \%$ & $0 \%$ & $0 \%$ & $0 \%$ & $0 \%$ \\
\hline & $-48 \%$ & $-49 \%$ & $-67 \%$ & $-34 \%$ & $-35 \%$ & $-44 \%$ & $-34 \%$ & $-39 \%$ & $-44 \%$ & $-43 \%$ \\
\hline & $-77 \%$ & $-73 \%$ & $-80 \%$ & $-68 \%$ & $-84 \%$ & $-87 \%$ & $-58 \%$ & $-62 \%$ & $-84 \%$ & $-75 \%$ \\
\hline & $-48 \%$ & $-28 \%$ & $-39 \%$ & $-54 \%$ & $-37 \%$ & $-47 \%$ & $-53 \%$ & $-35 \%$ & $-59 \%$ & $-50 \%$ \\
\hline Total & $-47 \%$ & $35 \%$ & $-20 \%$ & $-69 \%$ & $-21 \%$ & $17 \%$ & $-74 \%$ & $-35 \%$ & $-63 \%$ & $-70 \%$ \\
\hline \multicolumn{11}{|c|}{ Cumulative components of change in emissions $(\Delta), 2005-2075$, million metric tons of $\mathrm{CO}_{2}$} \\
\hline \multirow{5}{*}{$\begin{array}{l}\text { Activity } \\
\text { Regional } \\
\text { Sectoral } \\
\text { Intensity } \\
\text { Mix } \\
\end{array}$} & 34799 & 960 & 14310 & 2329 & 879 & 3461 & 375 & 555 & 2204 & 5274 \\
\hline & 7658 & 0 & 0 & 0 & 0 & 0 & 0 & 0 & 0 & 0 \\
\hline & -13238 & -250 & -5406 & -886 & -151 & -606 & -260 & -176 & -604 & -2165 \\
\hline & -29781 & -485 & -7791 & -2113 & -650 & -2052 & -444 & -364 & -1875 & -5133 \\
\hline & -12459 & -122 & -2323 & -1638 & -157 & -662 & -487 & -163 & -790 & -2386 \\
\hline Total & -13022 & 104 & -1210 & -2308 & -78 & 141 & -816 & -148 & -1064 & -4410 \\
\hline \multicolumn{11}{|c|}{ Cumulative components of change in emissions $(\Delta), \%$ difference from Scenario $2 c$ with CCS } \\
\hline \multirow{5}{*}{$\begin{array}{l}\text { Activity } \\
\text { Regional } \\
\text { Sectoral } \\
\text { Intensity } \\
\text { Mix } \\
\end{array}$} & $-1 \%$ & $-1 \%$ & $0 \%$ & $0 \%$ & $-2 \%$ & $1 \%$ & $0 \%$ & $1 \%$ & $-31 \%$ & $0 \%$ \\
\hline & 0 & 0 & 0 & 0 & 0 & 0 & 0 & 0 & 0 & 0 \\
\hline & $-2 \%$ & $0 \%$ & $-3 \%$ & $0 \%$ & $-1 \%$ & $-2 \%$ & $0 \%$ & $0 \%$ & $-2 \%$ & $-1 \%$ \\
\hline & $0 \%$ & $0 \%$ & $0 \%$ & $0 \%$ & $0 \%$ & $-2 \%$ & $0 \%$ & $-1 \%$ & $-1 \%$ & $0 \%$ \\
\hline & $5 \%$ & $1 \%$ & $12 \%$ & $0 \%$ & $5 \%$ & $12 \%$ & $0 \%$ & $2 \%$ & $3 \%$ & $2 \%$ \\
\hline Total & $3 \%$ & $0 \%$ & $10 \%$ & $0 \%$ & $2 \%$ & $10 \%$ & $0 \%$ & $1 \%$ & $0 \%$ & $1 \%$ \\
\hline
\end{tabular}




\section{Table 4}

\begin{tabular}{|c|c|c|c|c|c|c|c|c|c|c|}
\hline & \multicolumn{10}{|c|}{ Scenario $2 \mathrm{c}$ without Nuclear } \\
\hline & World & Brazil & China & EU15 & Indonesia & India & Japan & Korea & Russia & USA \\
\hline \multicolumn{11}{|c|}{ Cumulative $\%$ change in factors influencing the growth of $\mathrm{CO}_{2}$ emissions $(D), 2005-2075$} \\
\hline \multirow{5}{*}{\begin{tabular}{|l} 
Activity \\
Regional \\
Sectoral \\
Intensity \\
Mix
\end{tabular}} & $503 \%$ & $1227 \%$ & $1850 \%$ & $222 \%$ & $1123 \%$ & $2824 \%$ & $103 \%$ & $323 \%$ & $940 \%$ & $312 \%$ \\
\hline & $41 \%$ & & & & & & & & & \\
\hline & $-47 \%$ & $-48 \%$ & $-64 \%$ & $-35 \%$ & $-34 \%$ & $-42 \%$ & $-35 \%$ & $-40 \%$ & $-43 \%$ & $-46 \%$ \\
\hline & $-77 \%$ & $-73 \%$ & $-81 \%$ & $-67 \%$ & $-84 \%$ & $-85 \%$ & $-58 \%$ & $-63 \%$ & $-83 \%$ & $-72 \%$ \\
\hline & $-51 \%$ & $-28 \%$ & $-49 \%$ & $-53 \%$ & $-41 \%$ & $-57 \%$ & $-52 \%$ & $-20 \%$ & $-62 \%$ & $-51 \%$ \\
\hline Total & $-49 \%$ & $35 \%$ & $-30 \%$ & $-68 \%$ & $-23 \%$ & $7 \%$ & $-73 \%$ & $-26 \%$ & $-62 \%$ & $-69 \%$ \\
\hline \multicolumn{11}{|c|}{ Cumulative components of change in emissions $(\Delta), 2005-2075$, million metric tons of $\mathrm{CO}_{2}$} \\
\hline \multirow{5}{*}{$\begin{array}{l}\text { Activity } \\
\text { Regional } \\
\text { Sectoral } \\
\text { Intensity } \\
\text { Mix } \\
\end{array}$} & 34994 & 960 & 13785 & 2414 & 876 & 3379 & 389 & 594 & 2227 & 5555 \\
\hline & 7308 & 0 & 0 & 0 & 0 & 0 & 0 & 0 & 0 & 0 \\
\hline & -13048 & -248 & -4904 & -949 & -148 & -559 & -272 & -204 & -599 & -2452 \\
\hline & -29599 & -483 & -7784 & -2193 & -637 & -1942 & -457 & -408 & -1854 & -5104 \\
\hline & -13225 & -125 & -2834 & -1560 & -176 & -838 & -468 & -90 & -828 & -2321 \\
\hline Total & -13569 & 104 & -1737 & -2288 & -86 & 40 & -807 & -108 & -1054 & -4322 \\
\hline \multicolumn{11}{|c|}{ Cumulative components of change in emissions $(\Delta), \%$ difference from Scenario $2 c$ with Nuclear } \\
\hline \multirow{5}{*}{$\begin{array}{l}\text { Activity } \\
\text { Regional } \\
\text { Sectoral } \\
\text { Intensity } \\
\text { Mix } \\
\end{array}$} & $0 \%$ & $0 \%$ & $-1 \%$ & $0 \%$ & $-1 \%$ & $0 \%$ & $0 \%$ & $-1 \%$ & $1 \%$ & $-1 \%$ \\
\hline & 0 & 0 & 0 & 0 & 0 & 0 & 0 & 0 & 0 & 0 \\
\hline & $-1 \%$ & $0 \%$ & $0 \%$ & $-1 \%$ & $-1 \%$ & $0 \%$ & $0 \%$ & $-2 \%$ & $-1 \%$ & $-3 \%$ \\
\hline & $0 \%$ & $0 \%$ & $-1 \%$ & $0 \%$ & $0 \%$ & $-1 \%$ & $0 \%$ & $-2 \%$ & $0 \%$ & $3 \%$ \\
\hline & $2 \%$ & $0 \%$ & $3 \%$ & $1 \%$ & $1 \%$ & $3 \%$ & $1 \%$ & $17 \%$ & $0 \%$ & $1 \%$ \\
\hline Total & $1 \%$ & $0 \%$ & $0 \%$ & $1 \%$ & $0 \%$ & $0 \%$ & $1 \%$ & $10 \%$ & $0 \%$ & $2 \%$ \\
\hline
\end{tabular}




\section{Table 5}

\begin{tabular}{|c|c|c|c|c|c|c|c|c|c|c|}
\hline & \multicolumn{10}{|c|}{ Scenario 2c without Hydro } \\
\hline & World & Brazil & China & EU15 & Indonesia & India & Japan & Korea & Russia & USA \\
\hline \multicolumn{11}{|c|}{ Cumulative $\%$ change in factors influencing the growth of $\mathrm{CO}_{2}$ emissions $(D), 2005-2075$} \\
\hline \multirow{5}{*}{$\begin{array}{l}\text { Activity } \\
\text { Regional } \\
\text { Sectoral } \\
\text { Intensity } \\
\text { Mix }\end{array}$} & $502 \%$ & $1210 \%$ & $1843 \%$ & $222 \%$ & $1123 \%$ & $2821 \%$ & $103 \%$ & $325 \%$ & $936 \%$ & $313 \%$ \\
\hline & $44 \%$ & & & & & & & & & \\
\hline & $-47 \%$ & $-49 \%$ & $-65 \%$ & $-34 \%$ & $-34 \%$ & $-43 \%$ & $-34 \%$ & $-38 \%$ & $-43 \%$ & $-43 \%$ \\
\hline & $-77 \%$ & $-73 \%$ & $-78 \%$ & $-67 \%$ & $-84 \%$ & $-84 \%$ & $-58 \%$ & $-61 \%$ & $-83 \%$ & $-75 \%$ \\
\hline & $-53 \%$ & $-26 \%$ & $-52 \%$ & $-55 \%$ & $-42 \%$ & $-58 \%$ & $-53 \%$ & $-37 \%$ & $-63 \%$ & $-52 \%$ \\
\hline Total & $-49 \%$ & $33 \%$ & $-29 \%$ & $-69 \%$ & $-23 \%$ & $10 \%$ & $-74 \%$ & $-36 \%$ & $-63 \%$ & $-71 \%$ \\
\hline \multicolumn{11}{|c|}{ Cumulative components of change in emissions $(\Delta), 2005-2075$, million metric tons of $\mathrm{CO}_{2}$} \\
\hline \multirow{5}{*}{$\begin{array}{l}\text { Activity } \\
\text { Regional } \\
\text { Sectoral } \\
\text { Intensity } \\
\text { Mix }\end{array}$} & 34534 & 957 & 14067 & 2330 & 876 & 3455 & 376 & 552 & 2218 & 5264 \\
\hline & 7651 & 0 & 0 & 0 & 0 & 0 & 0 & 0 & 0 & 0 \\
\hline & -12886 & -255 & -5107 & -882 & -148 & -592 & -260 & -173 & -598 & -2150 \\
\hline & -28988 & -487 & -7393 & -2107 & -631 & -1889 & -444 & -358 & -1838 & -5103 \\
\hline & -14032 & -115 & -3238 & -1652 & -183 & -902 & -488 & -173 & -840 & -2468 \\
\hline Total & -13721 & 100 & -1671 & -2311 & -86 & 71 & -816 & -151 & -1058 & -4456 \\
\hline \multicolumn{11}{|c|}{ Cumulative components of change in emissions $(\Delta), \%$ difference from Scenario $2 c$ with Hydro } \\
\hline \multirow{5}{*}{$\begin{array}{l}\text { Activity } \\
\text { Regional } \\
\text { Sectoral } \\
\text { Intensity } \\
\text { Mix } \\
\end{array}$} & $-1 \%$ & $-16 \%$ & $-7 \%$ & $0 \%$ & $-1 \%$ & $-3 \%$ & $0 \%$ & $0 \%$ & $-3 \%$ & $0 \%$ \\
\hline & 0 & 0 & 0 & 0 & 0 & 0 & 0 & 0 & 0 & 0 \\
\hline & $-1 \%$ & $-1 \%$ & $-1 \%$ & $0 \%$ & $-1 \%$ & $-1 \%$ & $0 \%$ & $0 \%$ & $-1 \%$ & $0 \%$ \\
\hline & $1 \%$ & $0 \%$ & $1 \%$ & $0 \%$ & $0 \%$ & $0 \%$ & $0 \%$ & $0 \%$ & $0 \%$ & $0 \%$ \\
\hline & $0 \%$ & $2 \%$ & $-1 \%$ & $0 \%$ & $0 \%$ & $1 \%$ & $0 \%$ & $0 \%$ & $0 \%$ & $0 \%$ \\
\hline Total & $0 \%$ & $-1 \%$ & $1 \%$ & $0 \%$ & $0 \%$ & $3 \%$ & $0 \%$ & $0 \%$ & $0 \%$ & $0 \%$ \\
\hline
\end{tabular}




\section{Appendix A - Description of the Phoenix Model}

Phoenix is a global recursive dynamic computable general equilibrium (CGE) model comprised of 24 regions (listed in Table A.1) and 27 production and investment sectors (listed in Table A.2). The model is solved in five-year increments using the MPSGE subsystem (Rutherford, 1999) for GAMS (Brooke et al., 1999).

Table A.1-- Phoenix Regions

\begin{tabular}{|c|c|}
\hline Phoenix Regions & $\begin{array}{c}\text { GAMS set } \\
\text { symbol }\end{array}$ \\
\hline $\begin{array}{l}\text { Australia \& New } \\
\text { Zealand }\end{array}$ & anz \\
\hline Rest of World & row \\
\hline China \& Taiwan & c_t \\
\hline Japan & jpn \\
\hline Korea & kor \\
\hline South Asia & sas \\
\hline Indonesia & idn \\
\hline India & ind \\
\hline Canada & can \\
\hline USA & usa \\
\hline Mexico & mex \\
\hline Other Latin America & ola \\
\hline Brazil & bra \\
\hline $\begin{array}{l}\text { Central America \& } \\
\text { Caribbean }\end{array}$ & cac \\
\hline European Union 15 & eu15 \\
\hline $\begin{array}{l}\text { Other European } \\
\text { Union } 27\end{array}$ & oe 27 \\
\hline $\begin{array}{l}\text { Western Other } \\
\text { Europe }\end{array}$ & weo \\
\hline Eastern Other Europe & eoe \\
\hline Russia & rus \\
\hline Central \& Other Asia & coa \\
\hline Middle East & mes \\
\hline North Africa & naf \\
\hline Sub-Saharan Africa & ssa \\
\hline South Africa & zaf \\
\hline
\end{tabular}


Table A.2-Phoenix Industries.

\begin{tabular}{lcc}
\hline Industrial Sectors & $\begin{array}{c}\text { GAMS set } \\
\text { symbol }\end{array}$ & Demand Categories \\
\hline Fishing & fsh & Food Products \\
\hline Agriculture & agr & Food Products \\
\hline Forestry & frs & Durable Goods \\
\hline Coal* & col & Non-electric Energy \\
Oil* & oil & Non-electric Energy \\
Gas* & gas & Non-electric Energy \\
Transport Equipment & tre & Durable Goods \\
Mining \& Quarrying & omn & Durable Goods \\
Construction & cns & Services, Construction, Other \\
\hline Machinery \& Equipment nec & ome & Durable Goods \\
Clothing & t_l & Clothing \\
\hline Non-durable Goods & u_i & Non-durable Goods \\
Food \& Tobacco & f_t & Food Products \\
Paper Products \& Publishing & ppp & Non-durable Goods \\
\hline Wood Products & lum & Durable Goods \\
Refined Oil Products* & p_c & Non-electric Energy \\
\hline Chemicals, Rubber, Plastics & crp & Non-durable Goods \\
\hline Non-metallic Minerals & nmm & Durable Goods \\
\hline Iron \& Steel & i_s & Durable Goods \\
Non-ferrous Metals & nfm & Durable Goods \\
\hline Electricity* & ely & Electric Energy \\
Transport (other) & otp & Transport \\
\hline Water Transport & wtp & Transport \\
Air Transport & atp & Transport \\
\hline Unspecified Other & u_o & Services, Construction, Other \\
\hline Services & svs & Services, Construction, Other \\
Investment Goods & CGDS & \\
\hline *energy sectors & & \\
\hline
\end{tabular}

As elaborated below, model outcomes are the result of optimizing behavior by consumers and producers. With a given technology set, producers combine intermediate inputs and primary factors (land, physical capital, and labor) at least cost to produce outputs which are then sold as intermediate inputs to other producing sectors, traded as export goods, or sold to fulfill public and private sector final demand. Consumers are endowed with primary factors of production and receive income from rental of these factors to the producing sectors. Each region's government collects tax revenue which is used to purchase public goods and services. International transportation costs and export and import tariffs associated with each traded good are captured 
in the model. As discussed further below, trade between regions is modeled using the Armington and Heckscher-Ohlin specifications. A solution to the model is achieved when the general equilibrium conditions of market clearance, income balance, and zero profits are satisfied.

\section{A.1. Production}

Production is specified using nested constant elasticity of substitution production functions. This section provides diagrams of the structure of the nested CES production functions for each sector. Each arm of the tree diagram represents inputs to a particular nest, and each node represents the nest's output. The primary factors of production are commonly grouped into one nest, separate from the intermediate inputs. We further differentiate among the intermediate inputs, placing the energy commodities into a nest separate from the remaining material and services inputs. Finally, for each intermediate input, producers are able purchase a composite of domestic and imported inputs. 


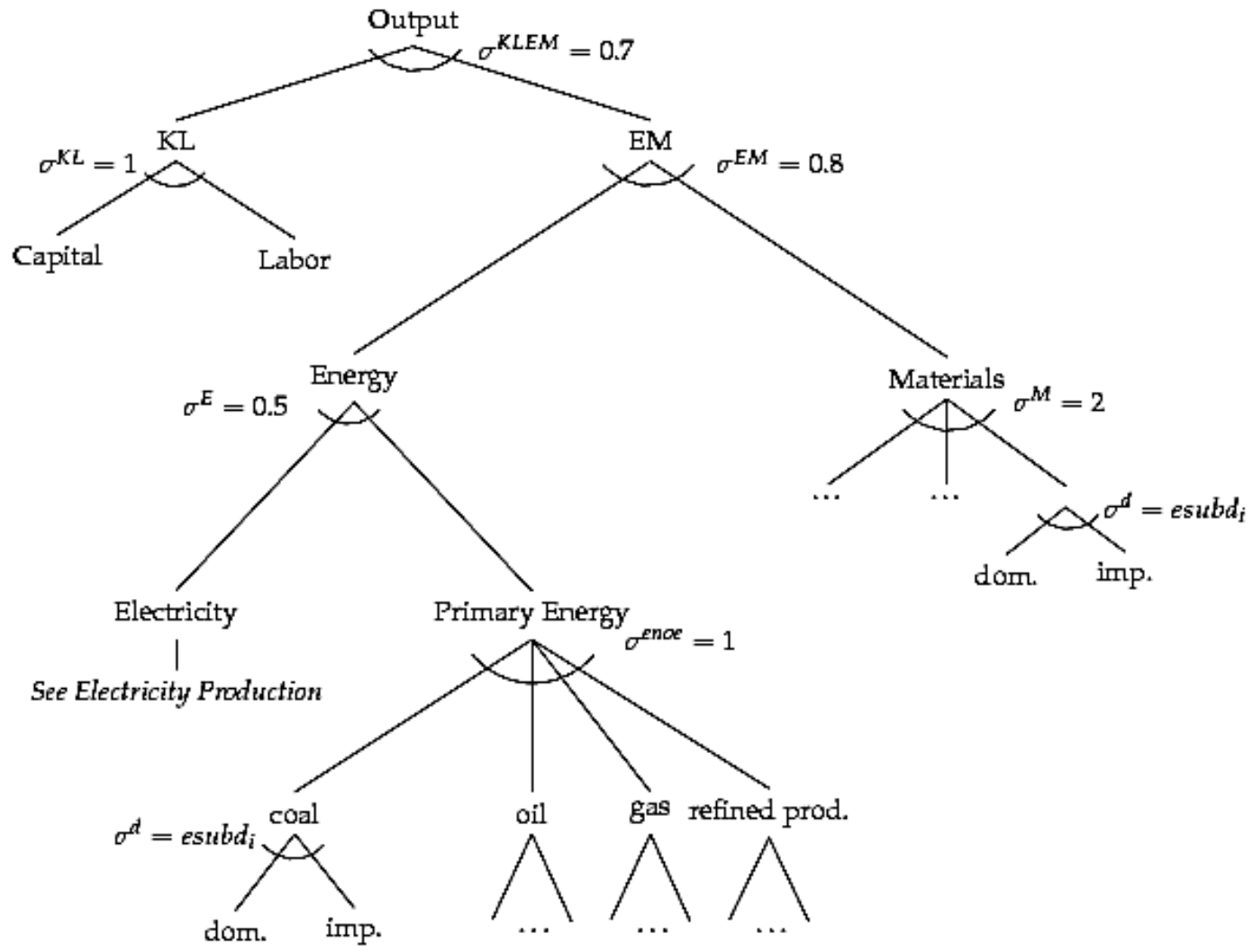

Figure A.1—Nested CES Production Function

Figure A.1 diagrams a typical nested CES production structure for the non-energy materials sectors in Phoenix. Working from the top, the elasticity of substitution between the capital-labor composite (KL) and an energy-material composites (EM) is $\sigma_{O}=0.7$. The $\mathrm{KL}$ composite is a Cobb Douglas aggregate of capital $(\mathrm{K})$ and labor $(\mathrm{L})$. The energy-materials composite $(\mathrm{EM})$ is an inelastic $\left(\sigma_{E M}=0.8\right)$ combination of the energy and material aggregates. The energy nest (E) comprises an aggregation of primary energy - a Cobb-Douglas composite of the four energy commodities - and electricity with an elasticity of $\sigma_{E}=0.5$. The materials composite is a highly elastic aggregate $\left(\sigma_{M}=2\right)$ of the twenty-one intermediate material inputs. Each material good is an Armington CES composite of domestic and imported varieties with an input-specific elasticity of substitution, $\sigma=e s u b d_{i}$, supplied by the GTAP database. With the 
exception of oil and gas commodities, which are traded as Heckscher-Ohlin (HO) goods, all intermediate inputs are traded as Armington goods; i.e., imported and domestic goods are assume to be imperfect substitutes. Armington trade (Figure A.2) is based on the theory that goods will be regionally differentiated. The Armington elasticity of substitution between goods from all exporting regions is $\sigma=e u_{b m}$.

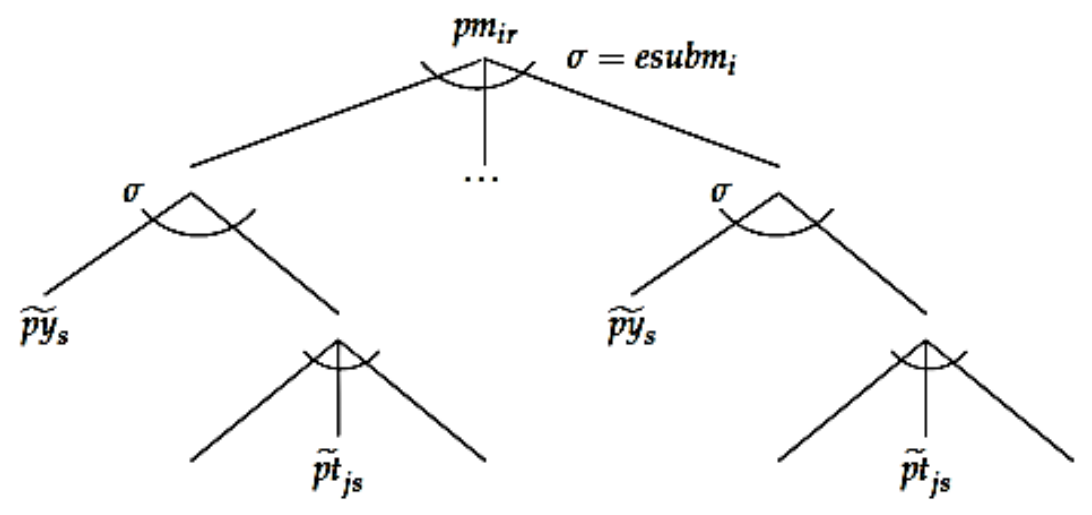

\section{Figure A.2-Armington Aggregation}

Transportation services, $p t_{i s}$, determine differences in unit transportation margins for each commodity and trading region. Export goods are subject to the export subsidy, $t_{i s r}^{x s}$, paid by government and corresponding import tariff, $t_{i s r}^{m s}$, paid by exporting companies to the government of importing region.

The production of coal, oil, gas, forestry, and agricultural products differs slightly from the nesting structured specified in Figure A.1. For these sectors, the KLEM composite is combined with the natural resource (see Figure A.3) to produce the final output. In the case of coal, oil, and natural gas production, the natural resource is the unprocessed energy resource. For agriculture and forestry outputs, the natural resource is land. The movement of land between the agriculture and forestry nests is modeled with a constant elasticity of transformation (CET) function, with an elasticity of transformation equal to 2 . 


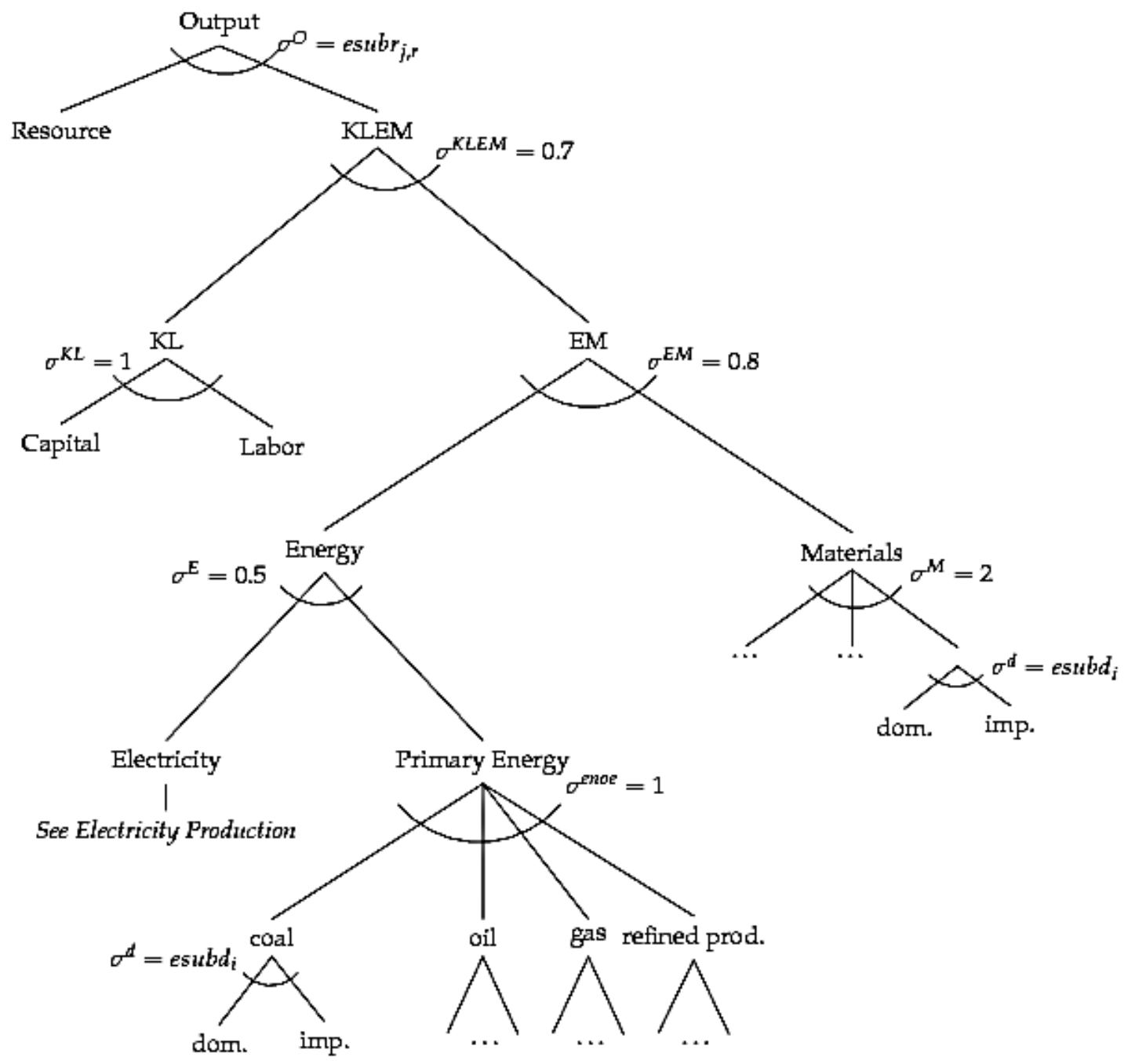

Figure A.3-Natural Resource Production

Electricity production (Figure A.4) varies substantially from the production structure of the other sectors. Producing electricity requires the generation of electricity from at least one of the nine generating technologies in combination with transmission and distribution services. Capital, labor and materials are inputs to the transmission and distribution nest. The electricitygenerating technologies are placed into three nests: base load, intermediate load, and peak load. There is Cobb-Douglas substitution between the base, intermittent, and peak loads, but we assume that there is a high measure of elasticity of substitution $(\sigma=4)$ between the generating technologies within each of these nests. 


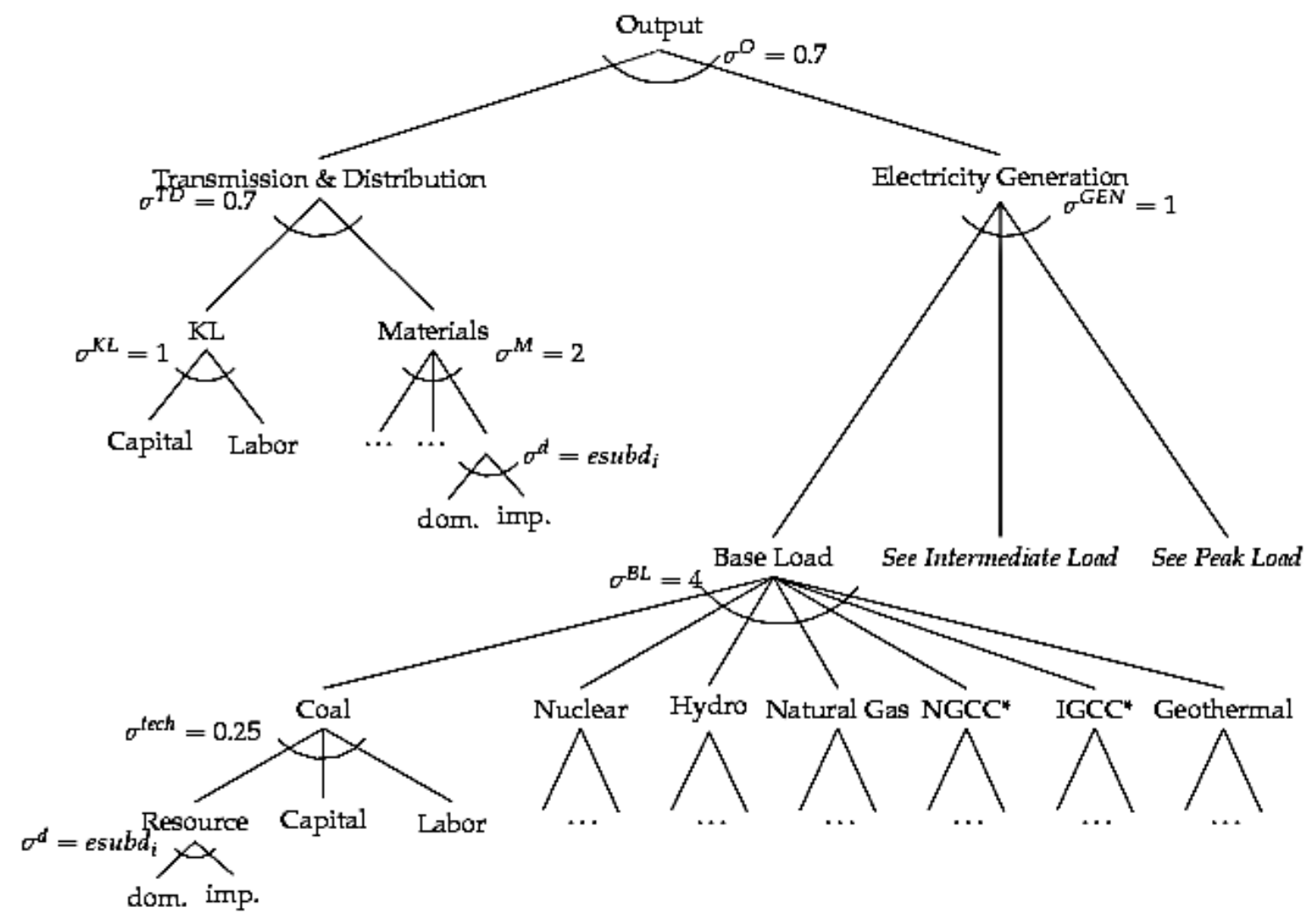

Figure A.4-Electricity Production

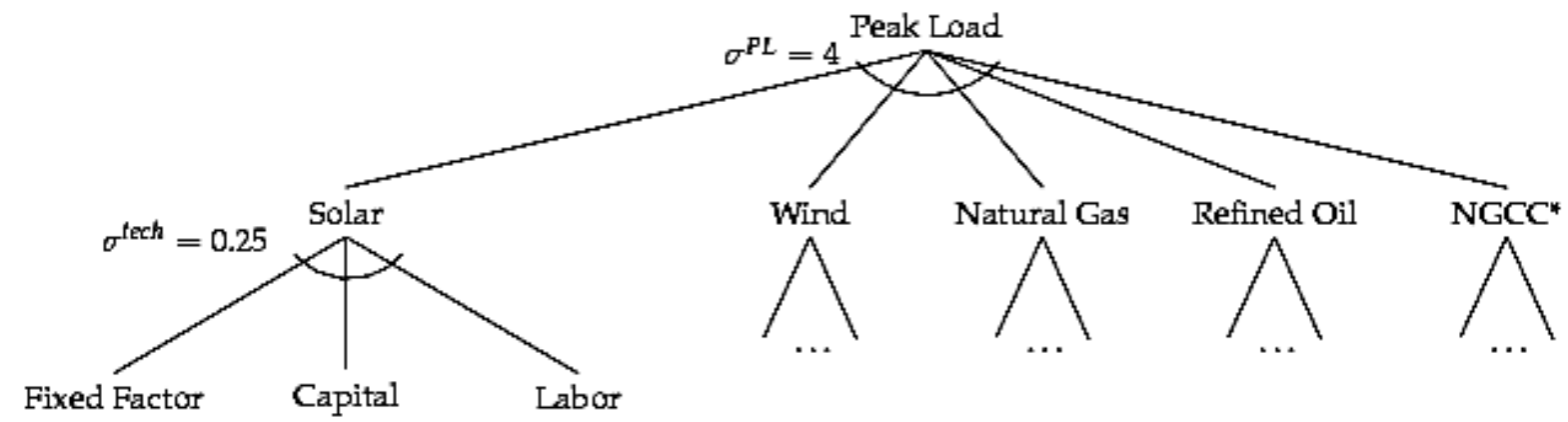

Figure A.5-Electricity, Peak Load Technologies 


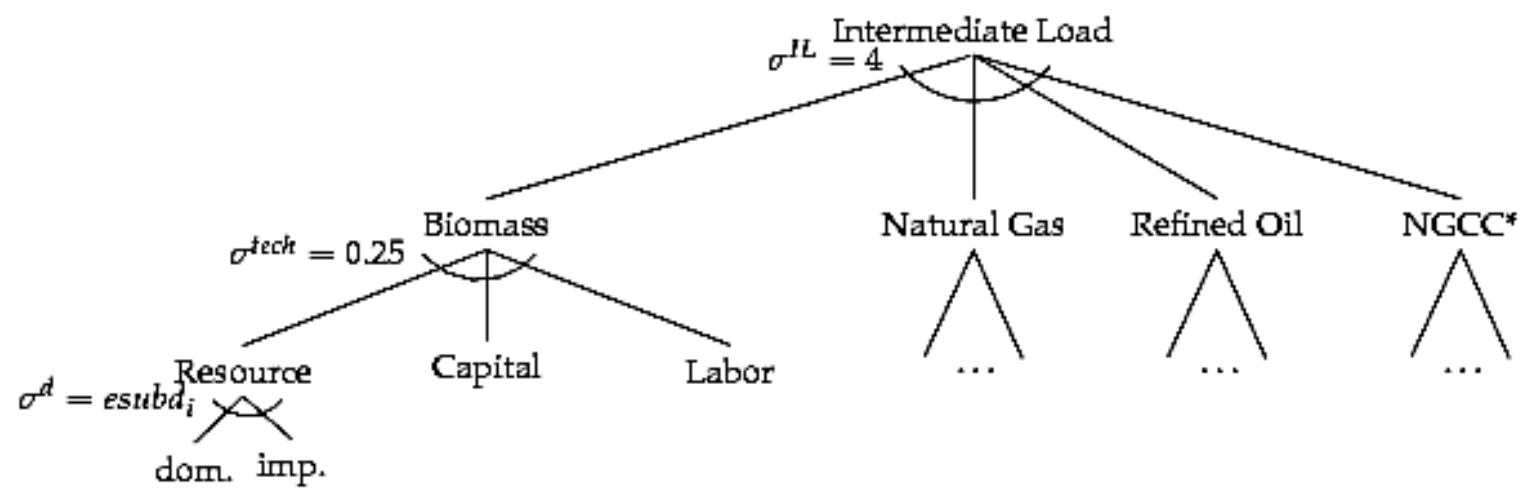

Figure A.6-Electricity, Intermediate Load Technologies

Electricity generation in each load nest is a CES aggregate of an array of discrete technologies.

Base load technologies include coal, nuclear, hydro-electric, geothermal, natural gas. We expect some combination of these technologies to be used to meet the continuous energy demands for a region at the lowest cost. In addition to these technologies, we include natural gas with carbon capture (NGCC) and coal integrated gasification with carbon capture (IGCC) as backstop technologies that become available in 2025 under the policy scenarios. Production of the backstop technologies is discussed below. Peak load technologies (Figure A.5) operate when a region's electricity demand is highest; on a daily basis, this typically occurs in the later afternoon and seasonally during the summer months. Current peak technologies include wind, solar, natural gas, and refined oil, and NGCC enters this nest under the policy scenario. The last nest (Figure A.6) includes the load-following, or intermediate, technologies that come online after base-generating technologies but before peak load technologies. Again, we assume that NGCC is a backstop technology in this nest and the current intermittent technologies include biomass, natural gas, and refined oil. 


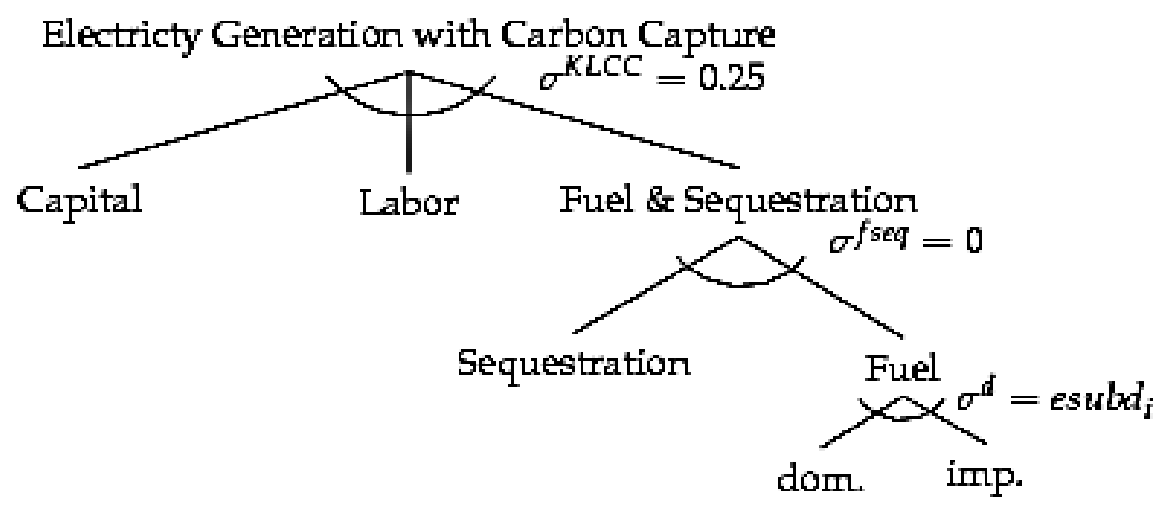

\section{Figure A.7-Electricity Generation with Carbon Capture Technology}

Electricity generated with ICGG and NGCC technologies differs from traditional fossil fuel electricity generation in that it requires an additional nesting level to integrate the carbon capture and storage technology (Figure A.7). The fuel and sequestration technology are combined assuming an elasticity of substitution of zero (i.e., Leontief), and then combined with capital and labor to generate carbon-free electricity.

Air and water transport are modeled using the nesting structure in Figure A.1. Ground transportation differs from air and water transport in that we allow for substitution away from conventional transport to hybrid electric (HEV) and/or biofuel backstop technologies when they are cost competitive (Figure A.8). The elasticity of substitution between conventional, HEV, and biofuel modes of transportation is assumed to be 1.2. 


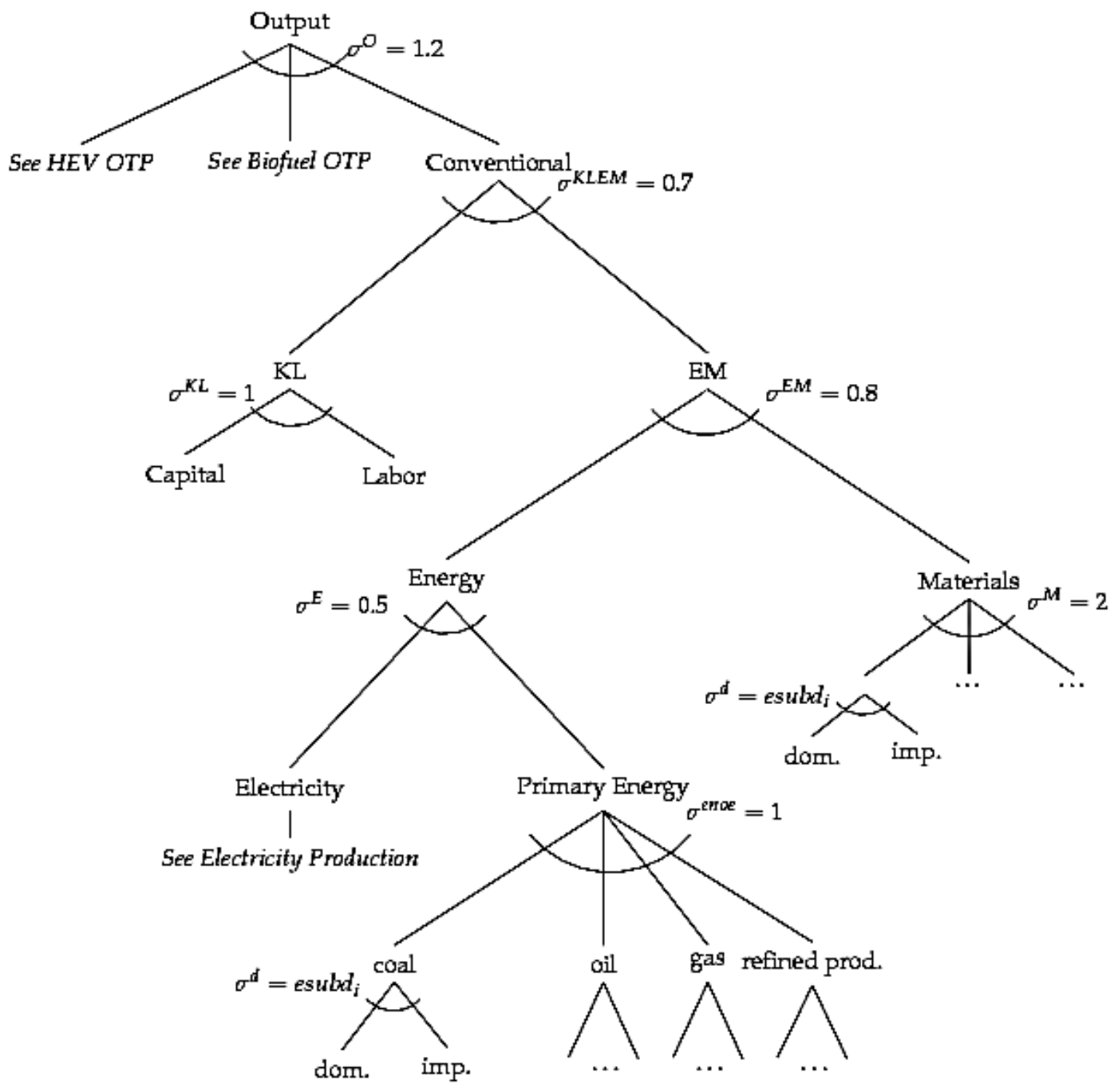

Figure A.8. Transportation 


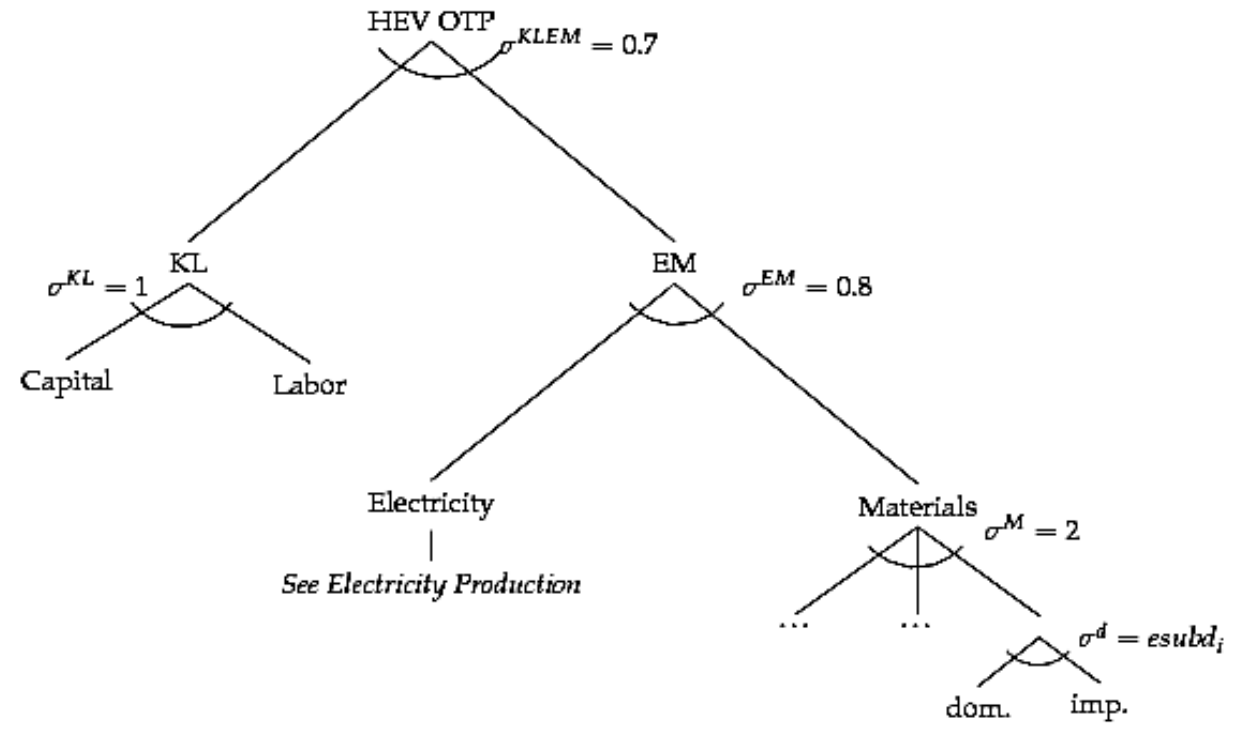

Figure A.9. HEV Transportation

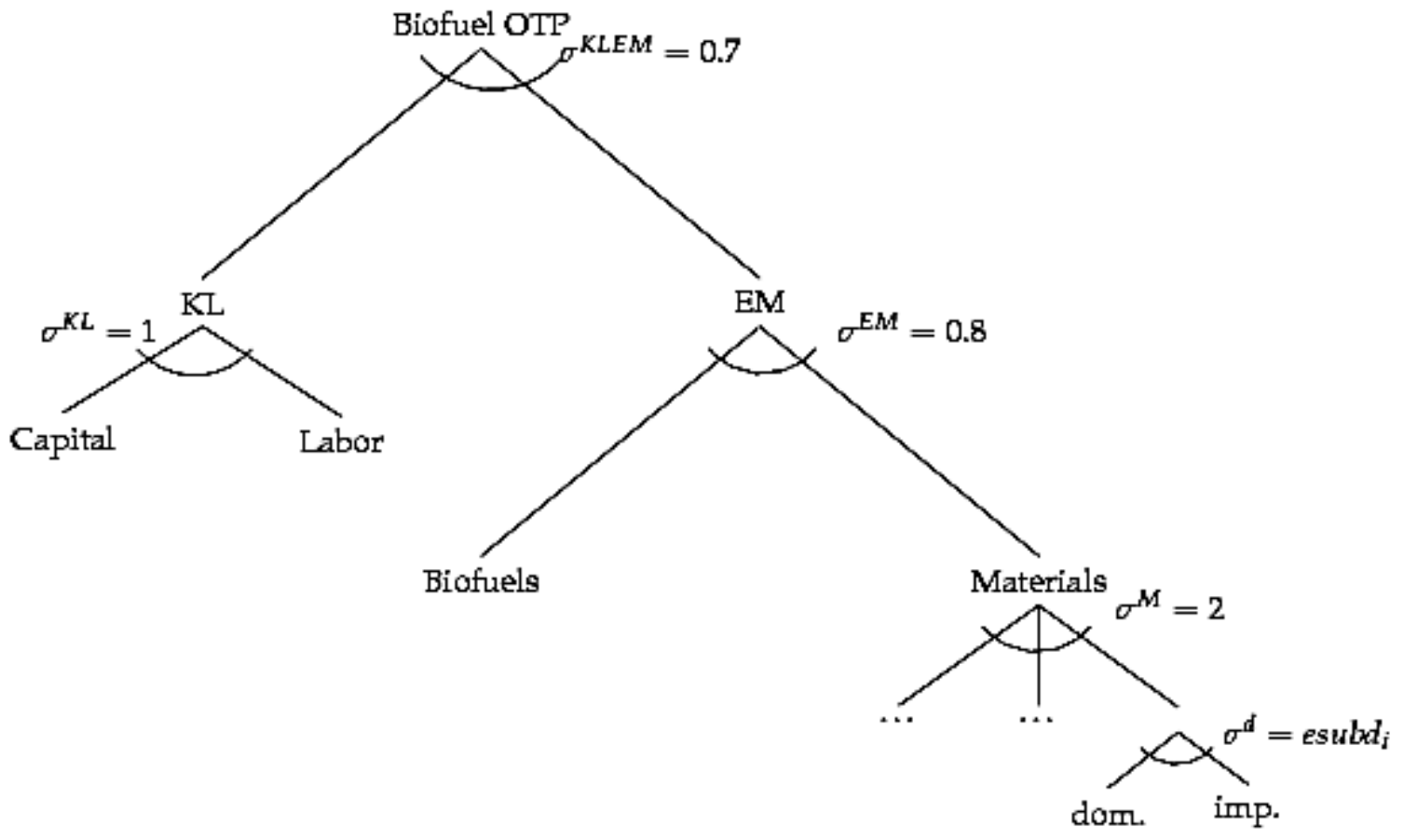

Figure A.10. Biofuel Transportation 


\section{A.2. Private and Public Consumption}

Private consumption comprises goods from the 26 industrial sectors (plus household own-supplied transportation), grouped into seven nests: clothing, non-durable goods, services, transport, food, durable goods, and energy (Figure A.11). Household own-supplied transportation is an additional consumption good created to account for the transportation resources used directly by households for personal transportation. The elasticity of substitution within each of the seven nests is 0.8 , and between the seven nests is 0.5 . There is an additional nesting level in the energy sub-nest, where non-electricity energy commodities are a CobbDouglas aggregation.

Similar to intermediate inputs in production, we assume that consumers are purchasing an Armington combination of imported and domestic products. In Phoenix there is a constant marginal propensity to save out of disposable income which, for simplicity, is implemented as a fixed relationship between consumption and investment.

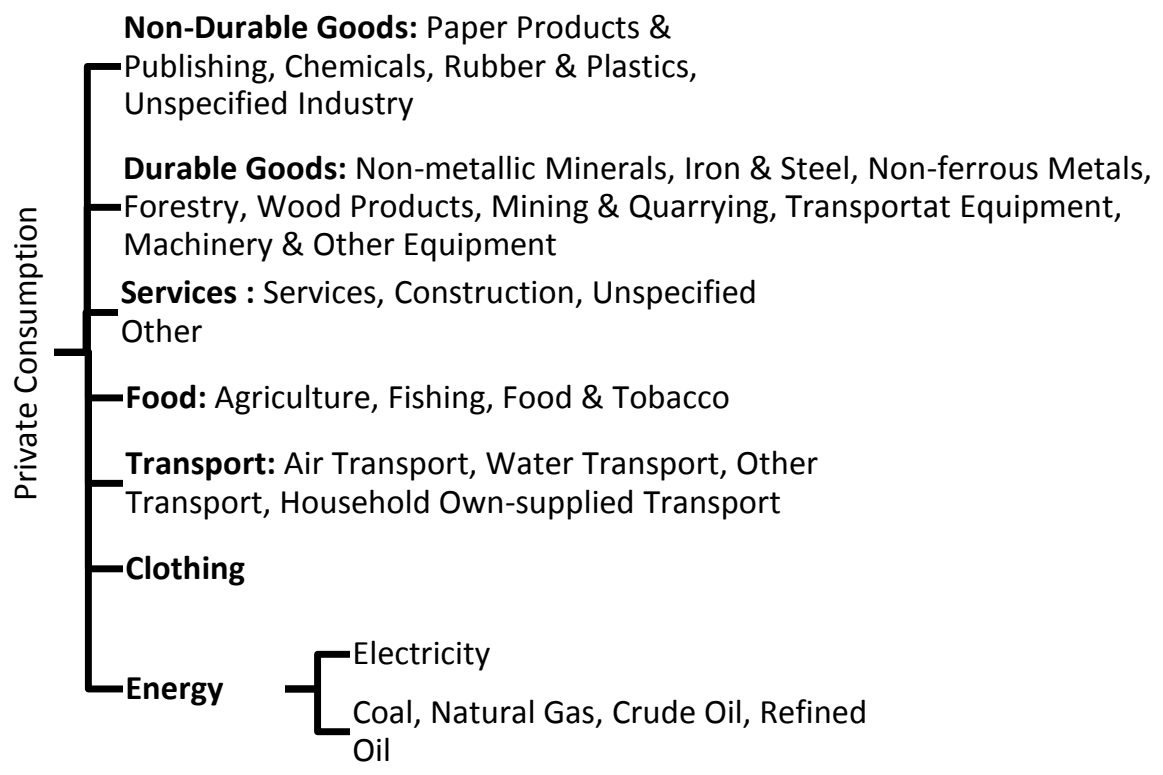

Figure A.11. Private Consumption 
Public consumption comprises two CES composites: energy and non-energy materials. The energy nest comprises a Cobb Douglas aggregation of the energy goods whereas we assume an elasticity of substitution of 2 between the goods in the materials nest.

\section{A.3. Dynamics}

The model is solved in five-year increments. After each time period, equilibrium prices and quantities are recorded, and capital and labor endowments are updated for the next period. The initial capital endowments in each region are taken from 2004 GTAP database and updated to 2005 using GDP growth rates from the Penn World Tables. Capital stock increases with private investment, $I_{t}$, and depreciates at a rate of $5 \%$ per year:

$$
K_{t+1}=K_{t}(1-\delta)+I_{t}
$$

Labor endowments beyond 2005 are exogenously defined using population growth projections and labor productivity values that reproduce the 2010 International Energy Outlook (IEA) projections. Fossil fuel resources are tracked, and a region's production of fossil fuel energy will become inactive once resources reach a specified lower bound.

Non-induced energy efficiency improvements are modeled using autonomous energy efficiency improvement (AEEI) parameters - a reduced form specification of the technologically-driven changes in energy consumption that allows a sector to maintain or exceed a given level of output while consuming fewer energy inputs. Average annual AEEI growth rates are set to achieve an average annual reduction in energy intensity of $1.7 \%$ across developing countries and a decrease of $1 \%$ in developed regions. This results in an average reduction in global energy intensity of $1.4 \%$.

\section{A.4. Data}


The benchmark data include 2005 social accounting matrices (SAM) obtained from the Global Trade and Analysis Project (GTAP) (Badri and Walmsley, 2008) and updated GDP growth rates from the Penn World Tables. Each SAM traces the flow of commodities and payments between a region's 26 industrial sectors, household and government, and rest of the world.

To provide a detailed analysis of the electricity sector, the GTAP electricity sector is disaggregated into the nine electricity-generating technologies modeled in Phoenix (coal, natural gas, oil, nuclear, wind, solar, hydro, geothermal, and biomass). This work utilizes the techniques outlined in Sue Wing (2006a and 2006b) and data on electricity production by technology compiled by the International Energy Association (IEA) and the Nuclear Energy Association (NEA) (IEA, 2005).

Benchmark data for household own-supplied transportation was obtained from Paltsev et al. (2004). Each region's oil, gas, and coal resource base is obtained from the Global Change Assessment Model (GCAM) (Edmonds et al., 1997), and is adjusted to match the Phoenix regions using distributions of energy resource data from MIT's Emissions Prediction and Policy Analysis (EPPA) model (Paltsev et al., 2005) and reserve adjustments from the Energy Information Association (EIA) databases.

\section{A.5. Emissions Accounting}

Currently carbon dioxide $\left(\mathrm{CO}_{2}\right)$ is the only greenhouse gas emission tracked in Phoenix. $\mathrm{CO}_{2}$ emissions are estimated from the level and type of energy consumed (coal, oil, and natural gas). We assume that the production of biofuels and biomass electricity is carbon neutral; the quantity of carbon generated by the combustion of biofuels in one year will be taken out of the 
atmosphere by re-growth of the biomass in subsequent years. The use of coal and natural gas carbon-capture and storage facilities produces no $\mathrm{CO} 2$ emissions.

Benchmark emissions data are obtained from GTAP. These data are used to generate $\mathrm{CO}_{2}$ emissions coefficients, $\operatorname{ccoe} f_{e, r}$, that represent the stoichiometric relationships between the quantity of a commodity demanded and the subsequent quantity of emissions produced. Using ccoe $f_{e, r}$ it is possible to measure the quantity of emissions generated by each production sector and through private and public demand as a function of carbon-based fuels consumed. In addition, a tax, $\tau^{\mathrm{CO}_{2}}$, can be leveled on each of the energy commodities relative to their carbon content. This shock enters the model as an increase in the price of carbon-based energy commodities. Carbon taxes collected in a region are returned to the representative consumer in a lump-sum fashion.

\section{A.6. CGE Accounting Identities}

Three conditions must hold to achieve equilibrium prices and allocations of goods and factors of production: market clearance (supply = demand), income balance (net income $=$ net expenditure), and zero profit. Market clearance requires the production of a good to equal the sum of public and private final demand, intermediate demand, investment demand, exports, and international transportation services. The income balance condition requires that household income equals expenditures. For the representative consumer, expenditures on consumption and investment goods are equal to the sum of income from factor rents net of tax payments.

Government revenues are generated by taxes and transfers. This includes both indirect taxes on production, imports and exports, and private and public consumption and direct taxes on households. Income balance requires that government revenue equals government expenditures. 
The zero profit condition requires that any activity with positive output must earn zero profits; specifically the value of a sector's inputs must be equal to or greater than the value of total output from that sector. This condition ensures that markets are perfectly competitive. In the producing sectors, value of output net of output taxes must equal the value of primary and intermediate inputs gross of the respective input taxes. 


\section{References}

Badri, Narayanan G. and Terrie L. Walmsley, Editors. 2008. Global Trade, Assistance, and Production: The GTAP 7 Data Base, Center for Global Trade Analysis, Purdue University.

Brooke, A.D., Kendrick, A. Meeraus, and R. Raman. 1999. GAMS: A User's Guide. GAMS Development Corp.

Copeland, B.R. and M.S. Taylor. 1994. "North-South trade and the Environment," Quarterly Journal of Economics, 109(3): 755-787.

Edmonds, J., M. Wise, H. Pitcher, R. Richels, T. Wigley, and C. MacCracken. 1997. “An Integrated Assessment of Climate Change and the Accelerated Introduction of Advanced Energy Technologies," Mitigation and Adaptation Strategies for Global Change, 1, pp. 311-39.

International Energy Association and Nuclear Energy Association. 2005. Projected Costs of Generating Electricity.

Kaya, Yoichi, and Keiichi, Yokobori. 1997. Environment, energy, and economy: strategies for sustainability. United Nations University Press.

Paltsev, S., H.D. Jacoby, J. Reilly, L. Viguier and M. Babiker, 2004, "Modeling the Transport Sector: The Role of Existing Fuel Taxes in Climate Policy," MIT Joint Program Report Series, Report 117. 
Paltsev, S., J.M. Reilly, H.D. Jacoby, R.S. Eckaus, J. McFarland, M. Sarofim, M. Asadoorian and M. Babiker, 2005, “The MIT Emissions Prediction and Policy Analysis (EPPA) Model: Version 4, MIT Joint Program Report Series, Report 125.

Rutherford, Thomas F. 1999. “Applied general equilibrium modeling with MPSGE as a GAMS subsystem: an overview of the modeling framework and syntax." Computational Economics, 14:1-46.

Sue Wing, Ian. 2006a. "The synthesis of bottom-up and top-down approaches to climate policy modeling: Electric power technologies and the cost of limiting US CO2 emissions." Energy Policy, vol. 34 pp. 3847-3869.

Sue Wing, Ian. 2006b. "The synthesis of bottom-up and top-down approaches to climate policy modeling: Electric power technology detail in a social accounting framework." Energy Economics, 28: 539-562. 